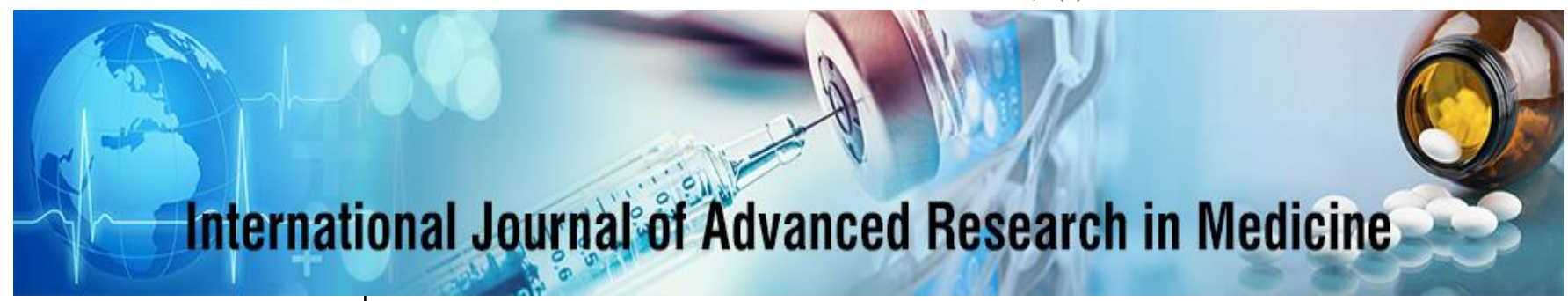

E-ISSN: 2706-9575

P-ISSN: 2706-9567

www.medicinepaper.net/ IJARM 2019; 1(2): 83-85 Received: 16-05-2019

Accepted: 18-06-2019

Thamer Mahdi Saleh Ministry of Health,

Baghdad Medical Office, Al-Karkh, Al Karkh General

Hospital, Baghdad, Iraq

Saadi Hameed Abbood

Ministry of Health, Baghdad Medical Office, Al-Karkh, Al Karkh General Hospital,

Baghdad, Iraq

Taleb Hassan Abbas Ministry of Health - Baghdad Medical Office - Al-Karkh, Al Karkh General Hospital, Baghdad, Iraq
Corresponding Author: Thamer Mahdi Saleh Ministry of Health, Baghdad Medical Office, Al-Karkh, Al Karkh General Hospital,

Baghdad, Iraq

\section{Surgical treatment of the non-frequent common symptomatic patella bipartite}

\author{
Thamer Mahdi Saleh, Saadi Hameed Abbood, and Taleb Hassan Abbas
}

DOI: https://doi.org/10.22271/27069567.2019.v1.i2b.22

\section{Abstract}

A bipartite symptomatic patella is a relatively common. However, a symptomatic bipartite patella is a rare condition. It can be chosen for a conservative or surgical treatment (for example excision of the patellar fragment). Current literature is not uniformly about the most successful treatment. We present a case report of a 26-year old patient with a painful knee, based on a bipartite patella. The super lateral patellar fragment was removed. After that, the vast us lateral muscle was sutured to the remaining patella. At follow-up in our out-door clinic after 8 weeks, the pain has been completely eliminated.

Keywords: Patella bipartita, ossification, chondral fracture, synchondrosis

\section{Introduction}

The patella bipartite is considered as a result of the incomplete fusion of native bone nuclei ${ }^{[1]}$. In that case, a synchondrosis occurs in the form of a patella bipartite, or even tripartite. In the scientific literature, the prevalence of the patella bipartite is estimated at $0.2-6.0 \%$. Of this, it is estimated that only $2 \%$ is symptomatic is caused, for example, by the occurrence of a chondral fracture ${ }^{[2-4]}$. A small part of the symptomatic group is eligible for surgical treatment. We present a case of a symptomatic patella bipartite that has been surgically treated by an open approach followed by functional after-treatment.

\section{Case}

A healthy 26-year-old man visited our outpatient clinic with crani lateral pain behind the patella that has existed for 3 months in the left knee, especially during incitement to walk, when cycling and when climbing stairs. He couldn't remember an acute traumatic moment. During physical examination there was pressure pain over the patella. Zohlen's test was also positive. There was no question of quadriceps atrophy or hydrops of the knee. Flexion and extension of the knee were complete. X-ray images of the knee showed a superolateral patella bipartita (Fig. 1). No abnormalities were visible in femur and tibia. An additionally made MRI scan showed edema in the synchondrosis, fitting the suspicion of a chondral fracture (Fig. 2). The symptomatic patella bipartita could be diagnosed. In consultation with the patient, surgical excision of the loose fragment was chosen via an open approach. Vast us laterals muscles was adhered to the remaining patella. As a follow-up treatment, the patient was instructed to flex a maximum of 40 degrees and to preserve strength perform isometric quadriceps exercises for 3 weeks. With outpatient check-up 8 weeks postoperatively, the pain symptoms had disappeared and the knee function was fully restored.

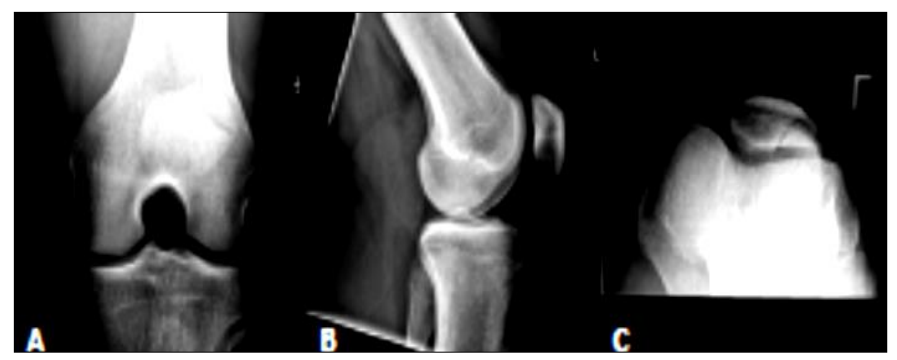

Fig 1: Preoperative X-rays of a superolaterally localized patella bipartita. (A) Port recording, (B) lateral and $(\mathrm{C})$ axial patella recording. 

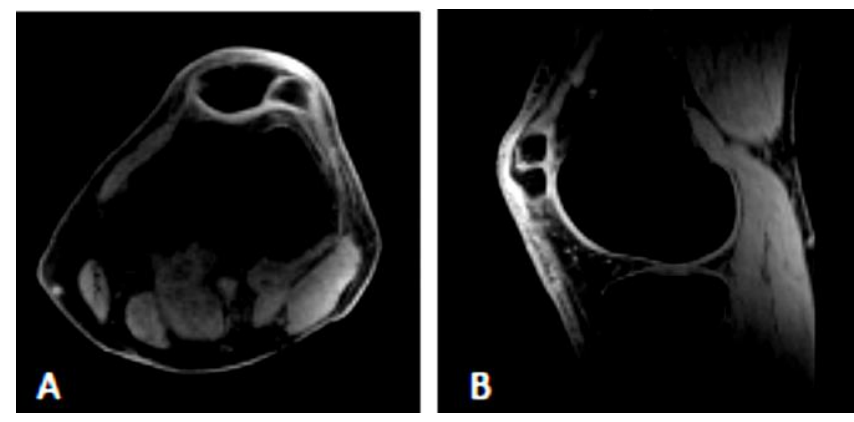

Fig 2: T2-weighted MRI images in (A) transversal and (B) sagittal plane with edema appearing in the synchondrosis.

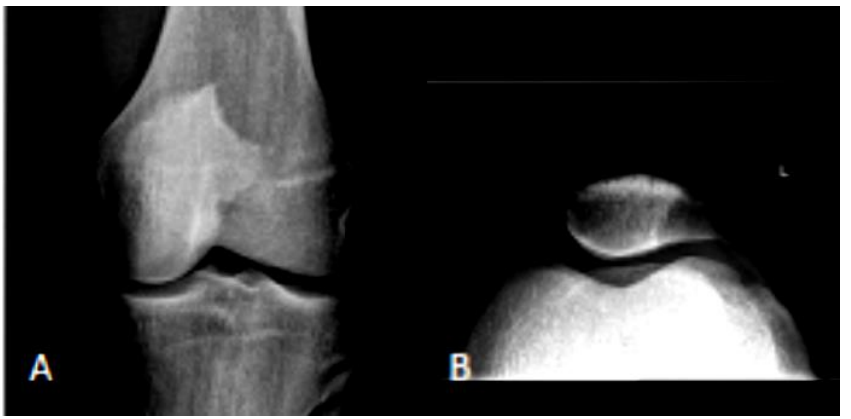

Fig 3: Post-operative X-rays after excision of the fragment. (A) Anteroposterior X-ray and (B) axial patella image.

\section{Consideration}

In the majority of cases the primary ossification of the patella takes place from one centrally located center, in the other cases the patella ossifies from several cores. Secondary ossification around the age of 10 takes place in the lower pole, the lateral aspect or the superolateral pole of the patella ${ }^{[5,6]}$. Not fully ossifying, resulting in a synchondrosis in the form of a patella bipartita or tripartita is only $2 \%$ symptomatic ${ }^{[2-4]}$.

The Zohlen test can be used to detect patellar or patellarfemoral problems, and in this case also to demonstrate a symptomatic patella bipartita. This test is also referred to as the 'patellar grinding test' or Clarke's sign, where 1. The leg is fully held in extension, 2. The proximal pole of the patella is fixed and the patella is moved distally and 3. After which the patient the quadriceps $\mathrm{m}$. The Zohlen test is scored positively if the patient experiences pain while tightening the quadriceps. A patella bipartita is considered symptomatic if the patient experiences pain in the patellar region, usually with an increase in symptoms during physical activity. Sometimes the pain arises peracutely after a knee trauma, where a chondral fracture can be seen. The peak prevalence of the patella bipartita is seen at the age of $13^{[7]}$. In $43-50 \%$ of the cases the condition exists bilaterally. The male to female ratio is $9: 1^{[2-4]}$.

There are several hypotheses about the pathophysiological mechanism that underlies the incomplete ossification of the patella. The most commonly used hypothesis is the failure of a fusion of the growth nuclei. Other authors are of the opinion that a traumatic mechanism, a non-union of a patella fracture at a young age, a dysbalance in tendinogenic traction or vascular insufficiency play a role. The (symptomatic) patella bipartita is probably a result of one or more of the above causes.

The first case concerning a patella bipartita was described by Gruber in $1883^{[8]}$. In 1921, Saupe published a classification system for the patella bipartita, which is still being used ${ }^{[9]}$. A type $\mathrm{I}$ is a synchondrosis of the inferior pole $(5 \%)$, a type II is a synchondrosis in the lateral edge (20\%), a type III is a synchondrosis in the superolateral pole $(75 \%)$. Oohashi et al. have added the patella tripartita to this classification: type IV is a lateral patella tripartita and a type $\mathrm{V}$ is a super-lateral patella tripartite ${ }^{[7]}$.

The literature often calls for a conservative treatment in the form of rest and NSAIDs. If complaints nevertheless persist, a surgical treatment can be chosen. If there is a suspicion of a chondral fracture, it is advised to opt for surgical treatment more quickly. However, due to the low prevalence of the patella bipartita and the low patient numbers in the published series, the scientific basis for this therapeutic algorithm is paper thin.

Non-operative treatment often leads to a good result. However, there is still a small risk of rupture of the knee extension device. Several case reports describe a traumatic chondral fracture in a patella bipartita, after which an avulsion fracture of the fragment occurs in the second instance. This can then again result in a rupture of the quadriceps and / or vastus medialis $m{ }^{[10-13]}$. Diabetes mellitus, male gender, age over 60 and obesity appear to be risk factors for such a complicated course.

The usual surgical treatment is ablative and not reconstructive in nature. After excision of the loose fragment, the vastus lateralis $\mathrm{m}$ can be fixed to the patella again. But for a large fragment, an osteosynthesis can be chosen to fix both fragments with screws or a zuggurtung. It is assumed that the long-term prognosis after reconstruction is good, but so far little is known about it after excision. Only Weckstrom et al. have one prospective series of 32 patients with symptomatic patella bipartita who were treated surgically. The average postoperative followup was 15 years (range 10 - 22 years) and led to a good functional outcome.

\section{Conclusion}

In this case, open surgical excision of the patella fragment has led to a good functional recovery and the patient is free of pain. If complaints do not disappear after conservative treatment, surgical excision seems useful. Because most studies have small patient numbers, the scientific basis for this advice is weak. Moreover, the long-term forecast is uncertain. More research into the outcomes of conservative or surgical treatments - with associated long-term follow-up - is needed.

\section{Reference}

1. Johnson K. Imaging in Pediatric Skeletal Trauma: Techniques and applications. Imaging in Pediatric Skeletal Trauma, 2008.

2. Kavanagh EC, Zoga A, Omar I, Ford S, Schweitzer M, Eustace S. et al. MRI findings in bipartite patella. Skeletal Radiol. 2007; 36(3):209-214.

3. Weaver JK. Bipartite patella as a cause of disability in the athlete. Am J Sports Med. 1977; 5(4):137-143.

4. Weckstrom M, Parviainen M, Pihlajamaki HK. Excision of painful bipartite patella: good long-term outcome in young adults. Clin Orthop Relat Res. 2008; 466(11):2848-2855.

5. Ogden JA, McCarthy SM, Jokl P. The painful bipartite patella. J Pediatr Orthop. 1982; 2(3):263-269.

6. Ogden YES. Radiology or postnatal skeletal development. X. Patella and tibial tuberosity. Skeletal 
Radiol. 1984; 11(4):246-257.

7. Oohashi Y, Koshino T, Oohashi Y. Clinical features and classification of bipartite or tripartite patella. Knee Surg Sports Traumatol Arthrosc. 2010; 18(11):14651469.

8. Gruber W. In Bildungsanomalie mit Bildungshemmung Bipartition beider Patellae eines jungen Subjectes. Virchows Arch. 1883; 94:358-361.

9. Saupe E. Beitrag zur Patella bipartita. Fortschr X-ray. 1921; (28):37-41.

10. Crankcase SR. Traumatic separation of a bipartite patella. Injury. 1989; 20(4):244.

11. Tonotsuka H, Yamamoto Y. Separation of a bipartite patella combined with quadriceps tendon rupture: a case report. Knee. 2008; 15(1):64-67.

12. Woods GW, O'Connor DP, Elkousy HA. Quadriceps tendon rupture through a superolateral bipartite patella. J Knee Surg. 2007; 20(4):293-295.

13. Thomas AL, Wilson RH, Thompson TL. Quadriceps avulsion through a bipartite patella. Orthopedics. 2007; 30(6):491-492. 